\title{
PARTIAL HEART BLOCK WITH DROPPED BEATS
}

\author{
BY \\ MAURICE CAMPBELL \\ From Guy's Hospital and the National Hospital for Diseases of the Heart
}

Received July 24, 1942

Partial heart block with dropped beats is, in my experience, generally found during acute infections or after too much digitalis. This is such a contrast with the ætiology of complete heart block, that it seems worth analysing a series of cases with all degrees of heart block, to see what association there is between partial block with dropped beats and complete block, and to define more precisely the conditions producing the former. The second part of the paper deals with the progressive changes found in the P-R intervals before and after the dropped beat.

\section{Clinical Observations}

There were 29 patients who had partial heart block with dropped beats without any higher degree of block. This was nearly one eighth of the total number ; but the condition is noticed less frequently than this would suggest, because generally it persists for a few days or weeks only, while in other types the degree of block is likely to be of long duration so that the patient is seen again, perhaps over a long period.

The occurrence of dropped beats is nearly always very transient, and most often due to an acute infection or to treatment with digitalis. The 11 cases in this last group have already been discussed (Campbell, 1942) and in 6 of them infection was an additional factor. In the 18 where it was not due to digitalis, 6 had acute rheumatism and 6 had other infections, most often acute tonsillitis that did not appear to be a manifestation of rheumatic fever. Thus, 12 of the 18 had active infection at the time : most of these were young adults. In the remaining 6 , who were nearly all older patients, there was no evidence of an active infection, and even when the condition was transitory it seemed to be a stage in their chronic disease or was observed at times without any obvious reason.

There were a further 9 cases, making 38 in all, where there was at one time partial heart block with dropped beats, and at other times a higher degree of block, such as $2: 1$ or even complete block (see Table I). Only 2 of these belonged to the group with active infection, and 7 to the older group with chronic disease.

TABLE

Etiology of Cases with Dropped Beats

\begin{tabular}{|c|c|c|c|c|}
\hline \multirow{2}{*}{ Ætiology } & \multicolumn{2}{|c|}{$\begin{array}{c}\text { Partial heart block with dropped beats } \\
\text { only }\end{array}$} & \multirow{2}{*}{$\begin{array}{l}\text { Partial block with } \\
\text { at other times } \\
\text { higher grades of } \\
\text { heart block }\end{array}$} & \multirow{2}{*}{ Total } \\
\hline & caused by digitalis & other causes & & \\
\hline $\begin{array}{l}\text { Acute rheumatism } \\
\text { Other acute infections, } \\
\text { mainly tonsillitis } \\
\text { Chronic myocardial disease* } \\
\text { Total number of cases }\end{array}$ & $\begin{array}{c}2 \\
1 \\
8 \dagger \\
11\end{array}$ & $\begin{array}{r}6 \\
6 \\
6 \\
18\end{array}$ & $\begin{array}{l}1 \\
1 \\
7 \\
9\end{array}$ & $\begin{array}{c}8 \\
21^{*} \\
38\end{array}$ \\
\hline
\end{tabular}

* Of the 21 cases, 3 were rheumatic ; the remainder in each group were almost equally distributed between (a) hyperpiesia, $(b)$ coronary atheroma, and $(c)$ heart failure or a large heart without proof of $(a)$ or $(b)$. $\dagger$ Infection was an additional factor in $\mathbf{3}$ of these.

\section{ÆTIOLOGICAL FACTORS}

1. Active infection. (a) Acute rheumatism. There were nine patients in this group. They did not seem to be quite representative of average cases of this disease, as a boy of 18 with a typical first 
attack (Case 13) was the only one under 24 years of age. Three had pericarditis. The first started with pericarditis and partial heart block and developed aortic incompetence (Case 1). The second had pericarditis and joint changes that were in some ways less like rheumatic than rheumatoid arthritis, and no evidence of valvular disease (Case 21). The third developed complete heart block at the start of a recurrent attack of theumatic fever (she already had aortic incompetence) ; this lasted for a week and was followed by partial block, sometimes with dropped beats, sometimes $2: 1$, and this persisted for three months : in spite of this she made an excellent recovery and was in good health twelve years later with very little change in these intervening years, although she did a fair amount of work running her father's house (Case 113, Campbell, 1931). Another man, aged 51, also escaped without permanent changes after a classical severe attack-the first and only other attack having been 38 years before (Case 22).

There was nothing special to say about the remaining patients, all of whom had established valvular disease before the attack in which dropped beats were observed, except that in three the recurrence causing the dropped beats seemed in other ways a trivial one. The cases are summarized in Tables II and III, and those caused by digitalis in Table II of the previous paper.

As has been noted in other series, the aortic valve was affected more frequently than in an average series of rheumatic cases, the figures being : aortic disease, 2 cases ; aortic and mitral disease, 1 ; mitral disease, 4 (in 2 the mitral involvement was slight) ; no valvular disease, 2 cases.

\section{TABLE II}

Dropped Beats, but no Higher Degree of Heart Block (18 cases) *

\begin{tabular}{l|c|c|c|c}
\hline & & \multicolumn{2}{|c}{ P-R interval } \\
$\begin{array}{l}\text { Case } \\
\text { No. }\end{array}$ & $\begin{array}{c}\text { Sex } \\
\text { and } \\
\text { Age }\end{array}$ & Diagnosis & $\begin{array}{c}\text { with dropped } \\
\text { beats }\end{array}$ & $\begin{array}{c}\text { without } \\
\text { dropped beats } \dagger\end{array}$
\end{tabular}

\section{Acute rheumatism}

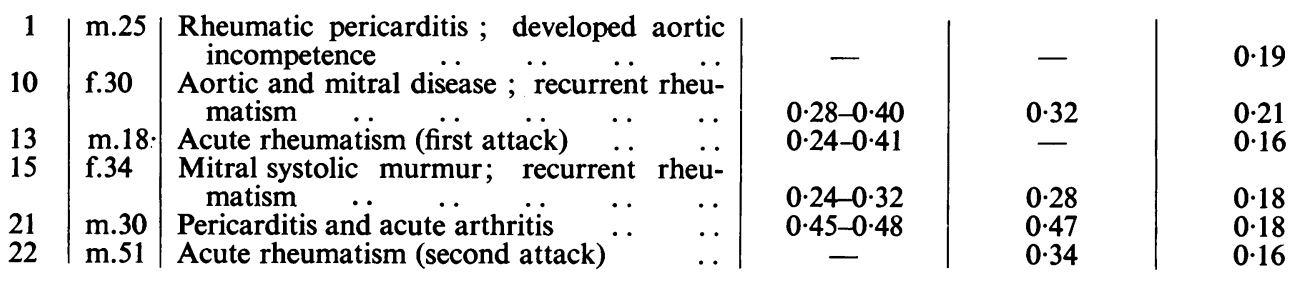

Other infections

\begin{tabular}{|c|c|}
\hline f.18 & Acute tonsillitis; early tuberculosis of lung \\
\hline f.23 & Tonsillitis; previously erysipelas $\ldots$.. \\
\hline f.21 & Quinzy and hyperthyroidism \\
\hline f.45 & Thyrotoxicosis; acute tonsillitis \\
\hline m.50 & $\begin{array}{c}\text { Recurrent dysentery; later slight sore } \\
\text { throat }\end{array}$ \\
\hline m.29 & $\begin{array}{c}\text { Tuberculosis of lungs; nephritis; enlarged } \\
\text { heart; dextrocardia }\end{array}$ \\
\hline
\end{tabular}

-
$0.20-0.40$
$0.28-0.38$
$0.35-0.42$
$0.29-0.56$

\begin{tabular}{l|l}
0.32 & 0.21 \\
0.32 & 0.16 \\
0.36 & 0.20 \\
0.26 & 0.18 \\
0.42 & $(0.28)$ \\
0.56 & -
\end{tabular}

Chronic Rheumatic

\begin{tabular}{l|l|l|l}
7 & $\mathrm{~m} .22$ & Mitral stenosis ; ? gonococcal myocarditis & $\mathbf{0} \cdot 20-0 \cdot 36$
\end{tabular}

$14 \quad \mathrm{~m} .52 \mid$ Rheumatic aortic incompetence .. . . $0.28-0 \cdot 44$

\section{Myocardial}

\begin{tabular}{r|l|ll}
3 & m.61 & Atherosclerosis; B.P. & 180/100 \\
6 & f.70 & Cerebral thrombosis; heart failure \\
16 & m.80 & Coronary atheroma & Corar \\
24 & m.66 & Enlarged heart; B.B.Bl. & $\ldots$
\end{tabular}

\begin{tabular}{ll|c}
$\ldots$ & $\cdots$ & $0 \cdot 25$ \\
& $\cdots$ & $0.24-0 \cdot 38$ \\
$\cdots$ & $\cdots$ & $\overline{0}$ \\
& $\cdots$ & $0 \cdot 24$
\end{tabular}

* Cases where the dropped beats were due to digitalis have not been included here (see Table II of the previous paper).

$\dagger$ In most cases the P-R interval when the heart block is latent is almost the same as the first P-R with a response at a time when there are dropped beats, but in cases $7,20,21,23$, and 29 it is almost the same as the last P-R interval before the dropped beat. 
TABLE III

Cases with Dropped Beats and at other Times a Higher Grade of Block (9 Cases).

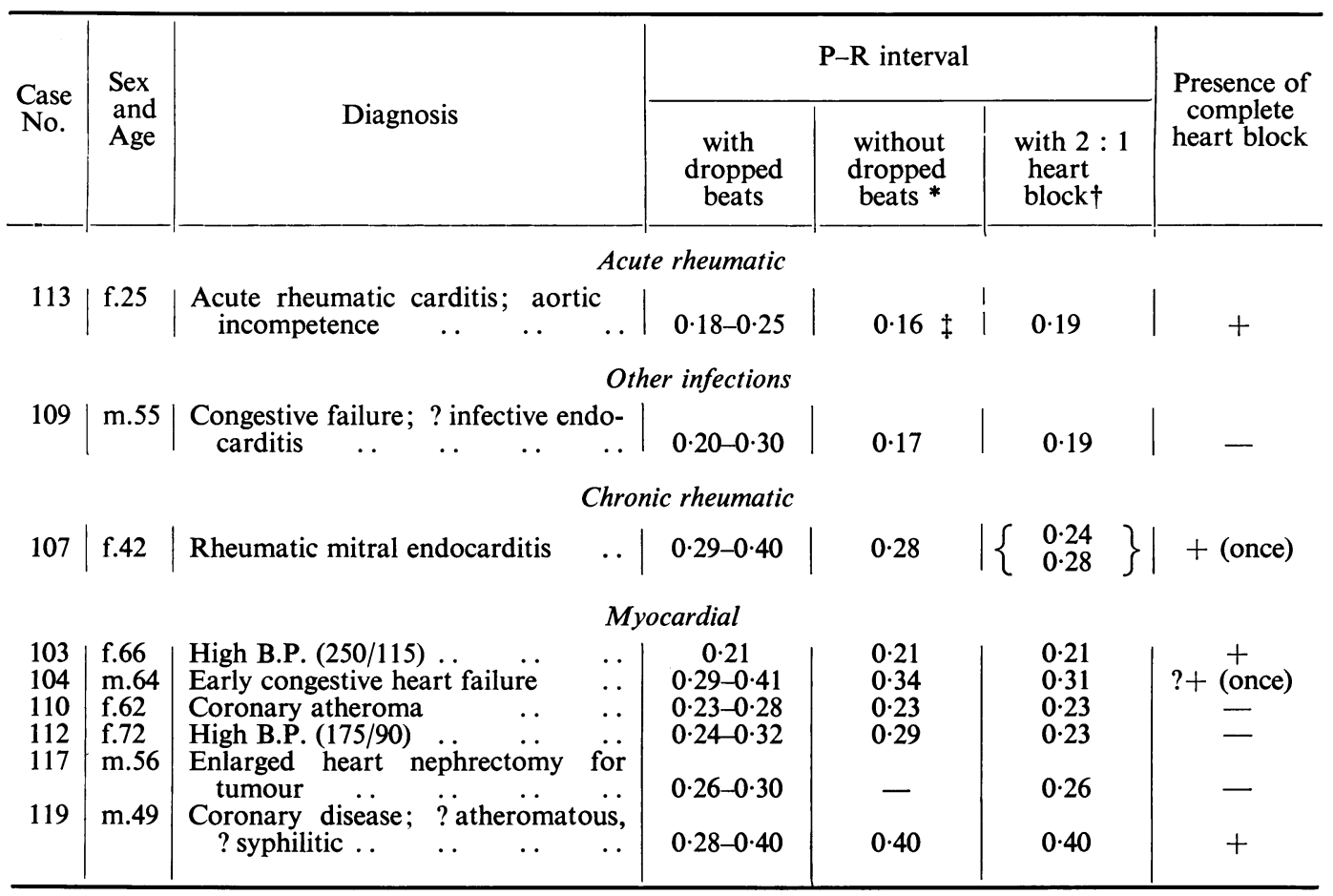

* The P-R interval of latent block is almost the same as the first P-R interval with a response, except in Cases 104, 112, and 119.

$\dagger$ The P-R interval with $2: 1$ heart block is almost the same as the first $\mathbf{P}-\mathbf{R}$ interval with a response, except in Case 119.

$\ddagger$ This was obtained at a later period, after recovery.

$1(b)$. Other active infections, mostly tonsillitis. There were eight cases in this group. Two of them were specially important because the dropped beats were caused by ordinary attacks of tonsillitis in patients with normal hearts. They are therefore described more fully below. It has been suggested that a prolonged $\mathbf{P}-\mathbf{R}$ interval in a young person is pathognomic of acute rheumatism, but there was not the slightest reason to suspect that these patients or their attacks of tonsillitis were rheumatic.

In three others, throat infections and thyrotoxicosis were associated (see p. 58). A sixth had congestive heart failure with some infection, probably infective endocarditis (Case 109). The seventh, having had bacillary dysentery several years before, was recovering from a relaspe and had a slight sore throat soon after the dropped beats had been found rather unexpectedly (Case 29). The eighth had advanced tuberculosis of the lung and a large white kidney, and died three weeks later with suppurative parotitis (Case 20).

Case 17. A nurse, aged 23, had erysipelas and was away for five weeks. She worked for three weeks with some tachycardia and then went to bed with a sore throat. Her temperature did not reach 100 , but after a few days dropped beats were suspected clinically, and she was sent for a cardiogram which showed a P-R interval of $0.32 \mathrm{sec}$. Within three weeks it had fallen to $0 \cdot 16 \mathrm{sec}$.

She has been under regular observation for ten years since and has never been off work or noticed any rheumatic or cardiac symptoms ; she may be a trifle short of breath, but no more than would be expected from her weight. There have been no physical signs in her heart, the P-R interval has remained at $0.16 \mathrm{sec}$, , and neither before nor since have there been any symptoms suggestive of rheumatism.

Case 5. A girl, aged 18, was admitted for a sore throat, malaise, and a pain in the right shoulder that had been present for five weeks. Her temperature was 101, but became normal in three days and her general condition quickly improved. There were some doubtful signs at the right apex, but after X-ray and sputum examination tubercle was exluded, wrongly, as was found later. Her heart rate on admission was 85 , but fell to about 44-56 during the first week and dropped beats were 
diagnosed. On the tenth day the P-R interval was 0.29 sec., inrceased to 0.32 after exercise. She was not sent for a cardiogram again and was discharged apparently well after a few weeks. She was written for four months later, when she looked and felt well and the P-R interval was $0.21 \mathrm{sec}$.; but when written for again after two years she was found to be in hospital with bilateral tuberculosis and died soon after.

2. Chronic heart disease. There were thirteen in this group, excluding those where the dropped beats were caused by digitalis. On the whole they were older patients, mostly about 60 . In this group, too, the dropped beats were generally transient. But in contrast with many of the younger patients, the underlying heart disease remained unchanged, and nearly always there was some permanent heart block; sometimes this was only latent, but often it was $2: 1$ or a higher grade of block. Complete heart block and Stokes-Adams attacks were indeed not uncommon in this group. These points are dealt with more fully and the findings contrasted with those in the younger group, where the dropped beats were due to active infection, in the discussion that follows.

\section{Discussion}

Age incidence. Excluding the cases caused by digitalis where all ages and types of disease were found, there was a complete contrast between the two groups of those with active infection and those with chronic heart disease. The average age of the fourteen patients with infections was 32 years ; all were between 18 and 51, and all but three between 18 and 34. The thirteen without active infection were nearly all over 60 . The average age of nine of them was as high as 67 , and the average of all thirteen was only kept as low as 59, because of two patients, aged 22 and 42. with mitral disease, one, aged 49, probably syphilitic (Case 119), and one, aged 52, with rheumatic aortic incompetence. The patient, aged 22, was exceptional in many ways and the dropped beats may have been due to a recurrent infection if his lesion really was a rheumatic mitral stenosis, because during several years when he was under observation with latent heart block this was the only time he had dropped beats, and later treatment with digitalis seemed more liable to change the rhythm to auricular fibrillation than to dropped beats. There was no rheumatic history but a very persistent gonococcal prostatitis (Case 7).

The transient nature of dropped beats. In the patients of both these groups the dropped beats were very transient and generally lasted for some days only. Naturally this was so in the cases where they were caused by infections or digitalis treatment, though in Case 113 the partial block was unusual by lasting for as long as three months.

More unexpectedly, it was nearly as transient in the older cases. Many of these were seen regularly or intermittently for five or six or even for ten or twelve years; and yet it was rare to have more than one or two plates with dropped beats unless these were taken about the same time. There was no patient with any reasonable expectation that dropped beats would be observed on any particular occasion he might be seen. The nearest approach to this was a doctor, aged 80 , with mild anginal symptoms who said that he had noticed dropped beats, sometimes one in four, sometimes one in twenty, for about six years ; I expected to find extrasystoles, but as the P-R interval was 0.30 sec. on both occasions he was seen, I think that he was correct, though I was not lucky enough to record any dropped beats (Case 16).

Prognosis, especially as regards the persistence of block. In the younger group due to infections, the heart block was often as transient as the dropped beats, so that the P-R interval returned to normal and the patient made a very good recovery with a heart that was nearly if not quite as good as before. This was specially true of the cases with uncomplicated tonsillitis and often of those with acute rheumatism.

The nurse with dropped beats after tonsillitis may be quoted, as within a few weeks her heart was thought to be normal and her history during the subsequent ten years bears this out (Case 17, see p. 57). She was the patient whose heart could with the greatest certainty be called normal, though there were others who seemed to make a complete recovery ; several even of the rheumatic patients made a surprisingly good recovery, for example the young woman quoted with transient complete heart block who is still in good health twelve years later. The degree of recovery of the $\mathbf{P}-\mathbf{R}$ intervals is well shown in Table II.

The only exceptions to this generally good outlook were the cases in which the infection was so severe that the patient died while still in the acute stage of his illness. The occurrence of heart block in cases where tonsillitis and hyperthyroidism were associated seemed of grave significance. There were three such patients, one having slight signs of hyperthyroidism and developing dropped beats after treatment with strophanthin when her septic tonsils had been removed (Case 28), one having a severe quinzy and slight evidence of hyperthyroidism (Case 23), and the other having exophthalmic goitre with partial heart block and dropped beats following an attack of tonsillitis (Case 25). The 
last two were among the small number of patients who died soon after dropped beats were observed ; the former died with a patchy myocarditis, and the latter died at home and was said to have had a pulse rate of 20 before her death (she was not placed in the group with complete heart block as this only included proved cases).

By contrast the older group generally had a long P-R interval or a higher degree of block permanently, even though the dropped beats were only observed for a time. Furthermore, there was permanent heart disease as the underlying cause : e.g. high blood pressure and atherosclerosis (Case 3), an enormous heart and bundle branch block (Case 24), atherosclerosis and a P-R interval of 0.30 sec. in a man of 80 (Case 16), congestive failure after a probable coronary thrombosis (Case 6), and so on ; and as might be expected the prognosis are mainly dependent on this. Actually only five of the thirteen died while they were under observation, but unfortunately less care was taken to keep in regular touch with these older patients.

Another difference was that the younger group generally had no higher degree of heart block than the dropped beats, while this was quite common with the older group. Only three of the seventeen in the younger group had higher degrees of block: viz. the girl who had complete heart block Jollowed by various grades of partial block during her acute rheumatism, and recovered without even latent heart block (Case 113) ; a woman of 45 with hyperthyroidism and tonsillitis who insisted on leaving hospital soon after her dropped beats had been recorded and died at home a few weeks later, probably with complete heart block (Case 25); and a man, aged 50, with congestive failure probably due to infective endocarditis, who had latent block, $2: 1$ block, and dropped beats within a few minutes on the same cardiogram (Case 109).

By contrast, rather more than half the older group with chronic heart disease had $2: 1$ heart block ; four of these were seen with complete heart block also, and one of them had a history of Stokes-Adams attacks. In addition, two of those, in whom neither $2: 1$ nor any higher degree of block was observed, gave a history (one certain and one doubtful) of Stokes-Adams attacks. A woman of 42 with rheumatic mitral disease may be taken as an example that the higher degree of block was the more usual finding in this group. Seen about twenty times in the course of five years, there was only one record with dropped beats, though latent block without dropped beats was seen several times in 1933 and in $1936:$ most often there was $2: 1$ heart block, though sometimes this was changing to latent, and once there was complete block. Her symptoms had started with one Stokes-Adams attack and she died suddenly six years later, presumably in another such attack (Case 107). Or again an elderly woman with high blood pressure who had dropped beats the first time she was seen : subsequently until her death six months later she generally had complete but sometimes $2: 1$ heart block (Case 103).

In conclusion, partial heart block with dropped beats was very transient. In two thirds of the cases it was due to acute infections or to digitalis treatment ; rheumatic fever was the most common, and tonsillitis the next most common infection. When it was due to infection, the patients were nearly all young, between 20 and 34, and generally made a very good recovery. In one third there seemed no obvious precipitating cause of the dropped beats. These were older patients, generally over 60, with chronic heart disease that was often serious, and in half of them a higher degree of heart block such as $2: 1$ was the usual rhythm.

\section{The Mechanism of Dropped Beats}

In 30 of the 38 cases the diagnosis was made on electrocardiographic evidence, so that the P-R intervals could be measured; in the other 8 , it was made by the clinical observation of dropped beats and a long $\mathbf{P}-\mathrm{R}$ interval in the cardiogram. These will be considered in two groups-a small number with no progressive increase of the $\mathrm{P}-\mathrm{R}$ interval and a larger number with progressive lengthening.

\section{Dropped Beats with no Previous Lengthening}

In 4 of the 30 cases the dropped beats occurred without any significant lengthening of the preceeding P-R interval. Lewis (1925, p . 177) states that this type of heart block due to "depression of excitability" was first described by Hay (1906) : his case showed $2: 1$ heart block with a normal a-c interval, and also the change from this to normal responses without any change in the a-c interval; there were no isolated dropped beats. This same type is, however, found in cases with dropped beats, the P-R interval being unchanged before and after the dropped beat, though generally prolonged.

The four cases of this type were an elderly woman with high blood pressure, who also showed $2: 1$ heart block, the P-R interval with all rhythms (latent and $2: 1$ block and dropped beats) being 0.21 sec. (Case 103): a man, aged 61, with high blood pressure, whose P-R interval was 0.25 sec. 


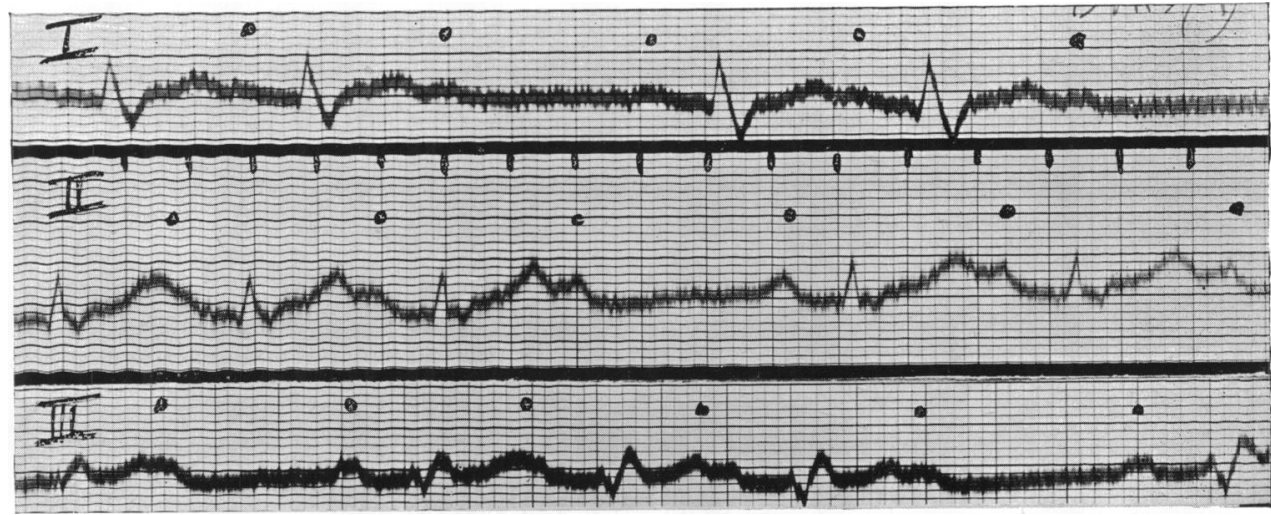

FIG. 1.-Fairly frequent dropped beats without any progressive lengthening of the $\mathbf{P}-\mathbf{R}$ intervals which are all about $0.25 \mathrm{sec}$. John Hay's depression of excitability. From an elderly man with atherosclerosis and high blood pressure. Case 3.

In this and succeeding figures the auricular waves have been marked with dots (.), and the time-marker rulings have been inked to show up fifths of a second.

whether he had dropped beats or only latent heart block (Case 3, Fig. 1: a man, aged 66, with a large heart and bundle branch block; whose irregular heart was generally caused by extrasystoles and sino-auricular block, but sometimes by dropped beats after his extrasystoles, the previous P-R intervals remaining unchanged at about $0.24 \mathrm{sec}$. (Case 24); and a man, aged 30, with pericarditis and acute arthritis, where the position was less definite, the P-R interval often remaining constant at 0.48 for many beats before one was dropped, but shortening a little to $0.45 \mathrm{sec}$. afterwards (Case 21, Fig. 2). Another case, seen recently, was a woman of 80 whose P-R interval was $0 \cdot 26$ (and had

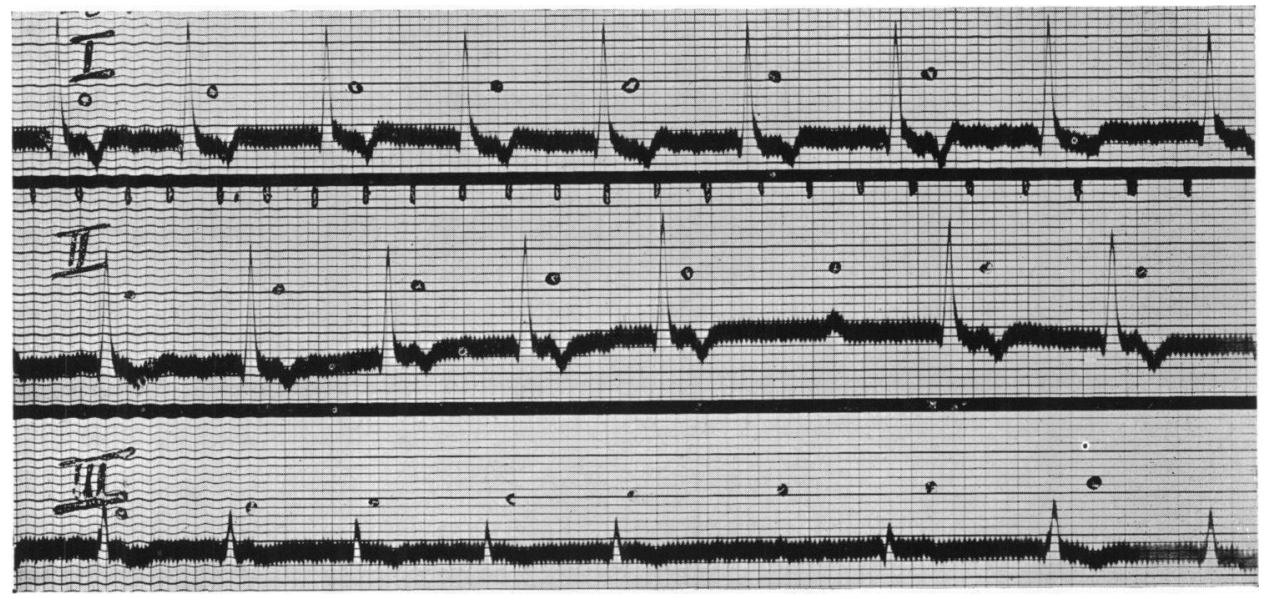

FIG. 2.-Occasional dropped beats interrupting very long $\mathbf{P}-\mathbf{R}$ intervals which are little changed. Those before the dropped beat were all $0.48 \mathrm{sec}$. and the one after was $0.45 \mathrm{sec}$. From a young man with pericarditis and rheumatism. Case 21.

been the same six months before when she had no dropped beats); she had also wide QRS waves and almost the picture of bundle branch block. Four of these five patients were elderly and of the type where complete heart block would not be an unexpected finding.

Other cases suggested that changes and intermediate types between this group and the more usual one with progressive lengthening of the P-R intervals (Wenkebach's periods) are not uncommon, e.g. a man where four or five P-R intervals before the dropped beat had a constant length of 0.44 , but one as short as to $0.28 \mathrm{sec}$. after the dropped beat (Case 14, Fig. 3). Another patient (Case 11), in whom the usual sequence of events was $0.24,0.42$ sec., d.b., etc., sometimes showed three or four final responses at a constant P-R of $0.42 \mathrm{sec}$. before the dropped beat.

Another with acute rheumatic carditis (Case 113), who showed all stages from one dropped beat after seven responses to 2:1 heart block, gave a sequence that resembles this to some extent in that 


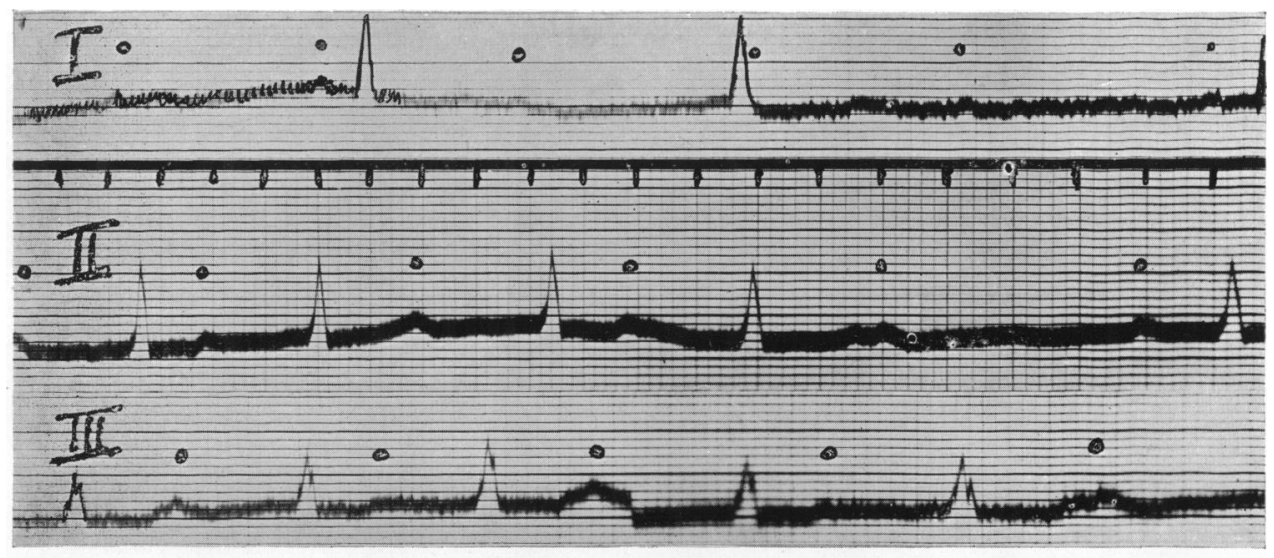

Fig. 3.-A dropped beat after a long series of unchanged $P-R$ intervals, each being 0.44 sec., but with much shortening of the P-R interval $(0.28 \mathrm{sec}$.) after the dropped beat. From a man with rheumatic aortic incompetence. Case 14.

the increase from 0.18 to $0.22 \mathrm{sec}$. during eight beats before a dropped beat seemed to remain steady in the middle period, e.g. $0 \cdot 18,0 \cdot 20,0 \cdot 21,0 \cdot 21,0 \cdot 21,0 \cdot 21,0 \cdot 22$, d.b. Inevitably as the number of responses before a dropped beat grows greater, the change in succeeding $P-R$ intervals must be less, but one of the longest we have measured with a dropped beat after eight responses was: $0 \cdot 28,0 \cdot 32,0 \cdot 32,0 \cdot 33$, 0.34, 0.37, 0·39, 0.40, d.b. (Case 10).

A young woman in whom dropped beats were only noted after vagal pressure in the neck (Case 23) may throw some light on the mechanism involved. Though at times her response was $0 \cdot 20,0.40$, d.b., etc., at other times it might be: 0.32 (6 times), 0.36 , d.b.; or $0 \cdot 20,0 \cdot 29,0.34$ (4 times); possibly because the effective pressure on the vagus was not sufficient to produce the first more usual response.

\section{Dropped Beats with Progressive Lengthening}

Omitting the 4 cases that gave dropped beats with no previous lengthening, there were 26 left to study the rate of lengthening of the P-R interval before the dropped beat. In some of these, various responses (e.g. $3: 2,4: 3,5: 4$, etc.) were observed (Cases 2 and 113 gave the most complete series for comparison in a single case); in others the responses were all of the same type. Naturally $3: 2$ heart block was seen most often (18 cases) and then $4: 3$ block ( 9 cases).

$3: 2$ Heart block. This was observed in 18 cases; in a few there was only a single record, but in the great majority there were at least three or four measurements, which would help to eliminate chance errors.

There were great variations in the length of the $P-R$ intervals in different patients, without any obvious relationship to the degree of heart block or to the type of diseased heart. Thus, the first P-R interval after the dropped beat might be a little below $0.20 \mathrm{sec}$. or as long as 0.30 ; the last before the dropped beat might be as short as 0.25 or as long as 0.40 ; and the difference between the two P-R intervals might be as much as 0.20 or as little as 0.10 or sometimes even $0.05 \mathrm{sec}$. These figures are given more accurately in Table IV; they were very much the same in the different grades of heart block. It was rather surprising to find this, as one might expect that where the first $\mathbf{P}-\mathbf{R}$ interval was $\mathbf{0 . 2 8}$, a dropped beat would be likely to occur sooner (i.e. after fewer responses) than in a case where it was only $0.20 \mathrm{sec}$. ; and that the difference between the first and last $\mathbf{P}-\mathbf{R}$ interval would be

TABLE IV

Variation in First and Last P-R Interval after and before a Dropped Beat

\begin{tabular}{c|c|c|c}
\hline Grade of heart block & First P-R & Last P-R & $\begin{array}{c}\text { Difference between first } \\
\text { and last P-R }\end{array}$ \\
\hline $3: 2$ & 0.18 to 0.29 & 0.26 to 0.42 & 0.046 to 0.20 \\
$4: 3$ & 0.18 to 0.29 & 0.25 to 0.41 & 0.07 to 0.17 \\
$5: 4$ & 0.17 to 0.29 & 0.27 to 0.43 & 0.045 to 0.21 \\
$6: 5$ & 0.19 to 0.28 & 0.26 to 0.43 & 0.07 to 0.16 \\
$7: 6$ & 0.18 to 0.28 & 0.23 to 0.44 & 0.045 to 0.22 \\
\hline
\end{tabular}


much greater where there were six responses before a dropped beat than when there were only two. It suggests, as do other findings, that more than a depression of conductivity is concerned in the production of dropped beats.

It was quite common for the P-R interval to lengthen to 0.40 or even $0.44 \mathrm{sec}$., as will be seen from figures of this magnitude occurring in each grade of heart block in Table IV. Exceptionally, however, as in a man who died with tuberculosis of the lungs and nephritis, it lengthened more than this, from 0.29 to $0.56 \mathrm{sec}$; ; later as his general condition became worse the heart rate quickened to 100 , but no further cardiogram was obtained (Case 20, Fig. 4).

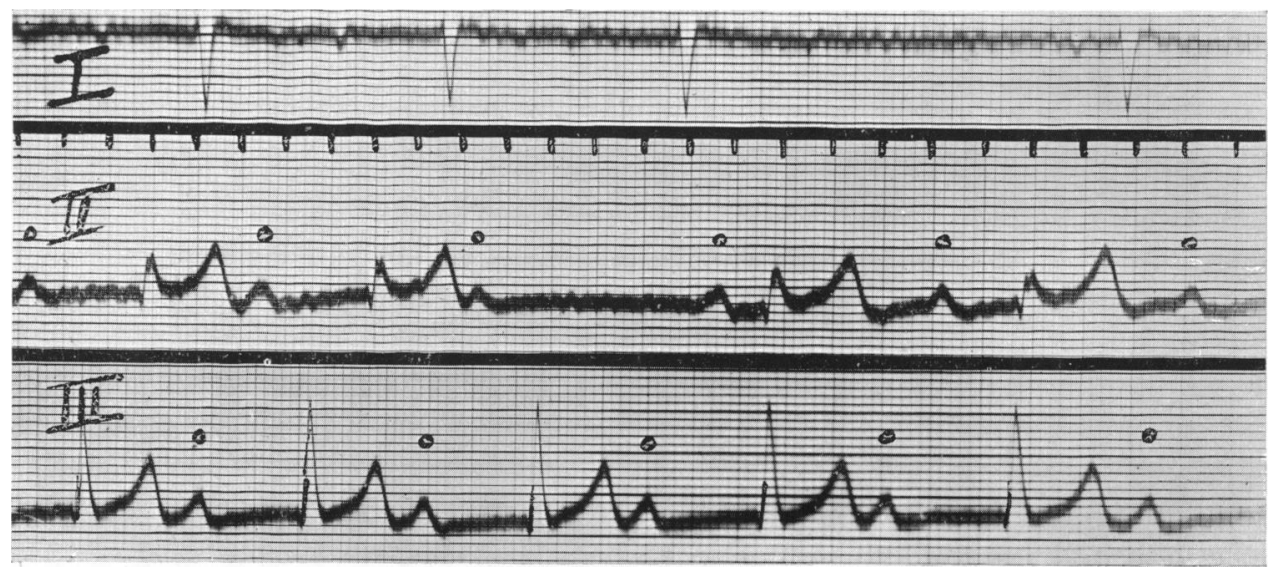

Fig. 4.- Unusually long $\mathrm{P}-\mathrm{R}$ intervals, $0.56 \mathrm{sec}$., sometimes very regular as in lead III, sometimes shortening considerably to $0 \cdot 29 \mathrm{sec}$., after a dropped beat as in lead II. From a man with tuberculosis, nephritis, and dextrocardia. Case 20.

I have not been able to find that any type of patient or type of heart disease is specially prone to fall into the groups with the longer or shorter P-R intervals. Taking the cases of any one grade of heart block there was some slight tendency for a short first P-R interval to be followed by a relatively short last P-R; e.g. if the cases were averaged in three groups according to the length of the first P-R interval the sequences were 0.19, 0.32, d.b.; 0.22, 0.35, d.b.; and 0.25, 0.36, d.b. But there was no close correspondence and there were many exceptions.

The average figure for the whole series (allowing a little extra weight to the cases where there were many records) was $0 \cdot 227,0 \cdot 347$, d.b., etc., but an arithmetical average without any weighting would have made little difference as this would have given the sequence $0 \cdot 232,0 \cdot 345$, d.b., etc.; subsequent figures were therefore obtained by the arithmetical average.

4:3 Heart Block. This was observed in nine cases and in most of them there were several measurements. There was again great variation in the first and last $P-R$ intervals and in the difference between them, these covering about as wide a range as with $3: 2$ heart block. Lewis (1925, p. 177) states: "It is the rule for the dropped beat to be foreshadowed by progressive lengthening of the $\mathrm{P}-\mathrm{R}$ interval. The increase of the second interval over the first is greater than the increase of the third over the second, or more generally: as the P-R interval increases the rate of increase in the P-R interval diminishes and the ventricular rate consequently quickens slightly." Six of the nine cases agreed with this, giving an average sequence P-R, 0.236, 0.304, 0.341, d.b., etc., the increment being 68 and 37, but in many of them the difference was not great. One (Case 13) showed this in an extreme form (Fig. 5) the sequence being $0.24,0.37,0.41$, d.b., etc. In the seventh the intervals were equal and in the eighth the sequence was $0 \cdot 18,0 \cdot 21,0 \cdot 25$, d.b. The ninth (Case 2) showed the reverse relationship, the sequence being $0.25,0.31,0.39$, d.b. The average figure for all nine cases was $0 \cdot 238,0 \cdot 297,0.340 \mathrm{sec}$., d.b., the first increment being greater than the second in the porportion of 59 to 43.

$5: 4$ Heart Block. There were five cases, all but one with two or more records that could be measured. There was the same variation in the first and the last $P-R$ intervals (see Table IV). The average figures were $0 \cdot 239,0 \cdot 281,0.314,0.349$, d.b., etc., and again the difference between the first two was the greatest but not to any very marked extent, the figures being $42,33,35$. Taking the individual figures they were more evenly spaced than in the other groups, but probably this was no more than chance. It was, however, significant that nearly all the cases in this group and the groups with higher grades of heart block were due to digitalis treatment or to acute infections. 


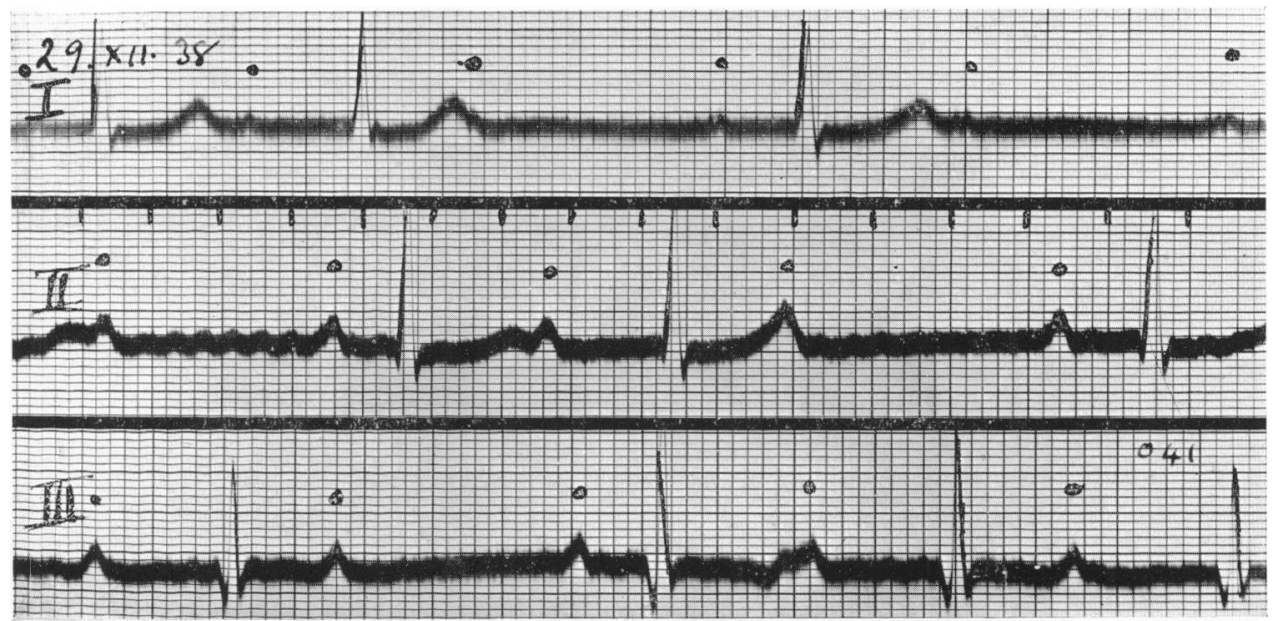

FIG. 5.-Generally $3: 2$ heart block (P-R, 0.25, 0.37, d.b., etc.), but at the end of lead III, 4: 3 heart block with Wenckebach's periods : P-R, 0.24, 0.37, 0.41 sec., d.b., etc. The amount by which the first increment exceeds the second is here exceptionally large, though it is usual for the first increment to be larger than the second or subsequent ones. From a young man with rheumatic fever. Case 13.

$6: 5$ and $7: 6$ Heart Block. Naturally there were fewer examples of these types and much stress cannot be laid on the average figures as they were only based on four and three cases respectively. There was much the same range in the first and last $\mathbf{P}-\mathbf{R}$ intervals and in the difference between them as in the higher grades of heart block discussed. The average sequence of $\mathbf{P}-\mathbf{R}$ intervals is shown in Fig. 6 and in Table $\mathrm{V}$ with the averages of the other groups. In both these groups the increment

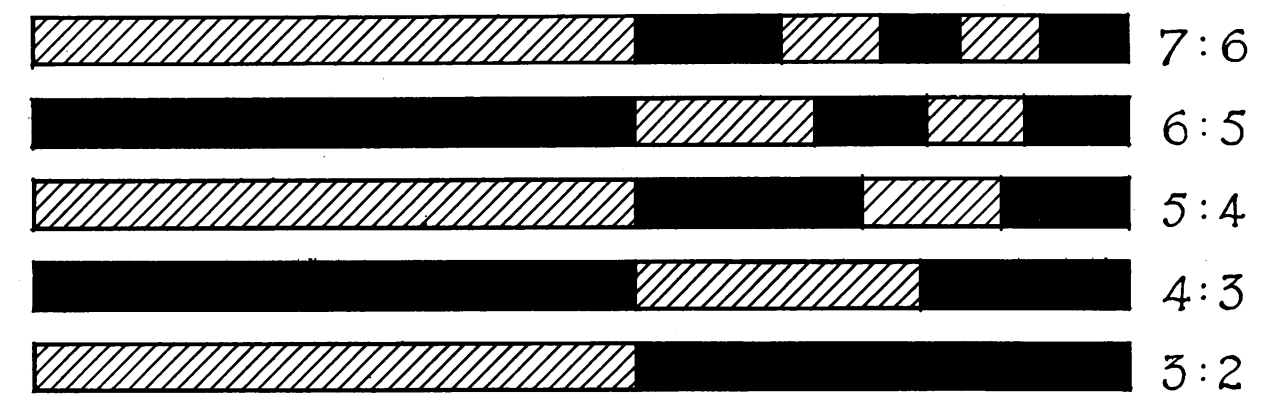

$$
\cdot 08 \cdot 10 \cdot 12 \cdot 14 \cdot 16 \cdot 18 \cdot 20 \cdot 22 \cdot 24 \cdot 26 \cdot 28 \cdot 30 \cdot 32 \cdot 34 \cdot 36
$$

FIG. 6. Diagram showing the length of the successive P-R intervals with different grades of heart block. Drawn from the smoothed figures given in Table VI.

was greatest between the first and second intervals, but after that the increment seemed to be fairly regular, the figures being 37, 22, 21, $25(6: 5)$; and 41, 22, 21, 20, $23(7: 6)$. In the last three groups there seemed a slight tendency for the last increment to be a little higher than any of the other figures except the first; in some individual cases it seemed to be more noticeable but rather inconstant.

\section{Discussion}

The average figures for the P-R intervals with different grades of heart block with dropped beats (d.b.) are shown below in thousandths of a second :

TABLE V

$3: 2$ heart block 227,347 , dropped beat.

$4: 3 \quad, \quad, \quad 238,297,340$, d.b.

$5: 4 \quad, \quad, \quad, \quad 239,281,314,349$, d.b.

$6: 5 \quad \Longrightarrow \quad$ ", 232, 269, 287, 308, 333, d.b.

$7: 6 \quad$ ", $\quad$ ", 226, 267, 289, 310, 330, 353, d.b. 
Wenkebach (1904) discussed this gradual lengthening of the a-c interval in his book on arrhythmia of the heart; he says " the interval is shortest at the first contraction after the pause, it is considerably longer at the second, and increases only a little more in length with succeeding systoles." He spoke of Luciani's periods and also described similar results obtained by Englemann in experiments with cardiac muscle; from this he deduced that it was due to a fundamental property of cardiac muscle and not to some special property of the fibres forming the block at the A-V groove.

Of two series of figures he quoted, chosen at random, $0 \cdot 235,0 \cdot 30,0.322,0.345,0.365$, d.b.; and $0.23,0.37,0.40,0.43,0.45 \mathrm{sec}$., d.b.; the former is near to the average found in this series and the latter is an instance where the first increment exceeds the other increments by much more than usual. Basing his arguments on his own work (Über den regelmässig intermittierenden Puls, 1899), and especially on that of Mackenzie, he argued that clinical heart block is a defect of conductivity. Partly as a result of his work, this is now so widely recognized that the difficulty of accepting it as the whole explanation is sometimes forgotten - a point which will be discussed later.

To return to the figures obtained in this series: the first P-R interval averaged $0.232 \mathrm{sec}$. and the last $0.345 \mathrm{sec}$. As some were above and some below this without any regular graduation, one can get a better comparison of the intermediate figures by adjusting all the first figures to 230 and all the last to 350 with corresponding adjustments of the other figures. There will still be irregularities due to errors and the small sampling, but by plotting out the figures and drawing smoothed curves one gets a more regular series of figures which are probably a better approximation to the truth; these are shown below.

TABLE VI.

\begin{tabular}{|c|c|c|c|}
\hline & \multirow{5}{*}{$\begin{array}{l}230,350 \text {, dropped beat. } \\
230,300,350, \text { d.b. } \\
230,286,319,350, \text { d.b. } \\
230,275,303,327,350, \text { d.b. } \\
230,266,292,312,332,350 \text {, d.b. }\end{array}$} \\
\hline & & & \\
\hline & & & \\
\hline & & & \\
\hline & & & \\
\hline
\end{tabular}

The first group of figures were submitted to Professor W. A. H. Rushton of Cambridge with the request for a mathematical formula covering their relationship. He very kindly considered the problem and wrote that the following formula has no arbitrary constants, is easy to compute, and seems to fit on the whole pretty well. If the grade of heart block is $\mathrm{N}+1: \mathrm{N}$, the $\mathrm{P}-\mathrm{R}$ interval for the $n$th beat after a dropped beat is given by T in thousandths of a second, where

$$
\mathrm{T}=250+120 \frac{n-1}{\mathrm{~N}}-\frac{20}{10^{n-1}}
$$

The corresponding figures calculated from this formula agree fairly well with the observed figures, except in the case of the second beat with $3: 2$ heart block where the calculated figure is much smaller; they are :

\section{TABLE VII}

\begin{tabular}{|c|c|c|c|}
\hline & \\
\hline & & $3: 2$ heart block & \\
\hline & " & $"$ & , \\
\hline & $"$ & $\because$ & , \\
\hline & , & , & $230,268,290,310,330,350,(370)$ \\
\hline
\end{tabular}

It thus appears from Professor Rushton's figures the beat is dropped when the P-R interval would have become as long as $\mathbf{0 . 3 7} \mathrm{sec}$. Looking at the same problem in a slightly different way $\mathrm{I}$ had concluded that there was a response when the P-R interval was $0.35 \mathrm{sec}$, , but not when it reached a longer time than this. One must remember that these are average figures and that in individual cases they may be a good deal higher or lower.

In 15 cases it was possible to make a comparison between the $\mathrm{P}-\mathrm{R}$ interval at the times when there were and when there were not dropped beats. With the dropped beats, the average P-R interval increased from $0.26 \mathrm{sec}$. to $0.37 \mathrm{sec}$.: without the dropped beats, it was $0.30 \mathrm{sec}$, an intermediate figure nearer to the $\mathrm{P}-\mathrm{R}$ interval of the first response after the dropped beat. Actually, in 7 cases it was the same as the P-R interval of the first response, and only in 3 cases was it the same as the $\mathbf{P}-\mathbf{R}$ interval of the last response before the dropped beat.

In 9 cases (Table III) one could also compare the P-R interval with $2: 1$ heart block. The average figures were : first response after the dropped beat, $0 \cdot 24$; last response before a dropped beat, 0.34 ; latent heart block with no dropped beats, $0 \cdot 27$; and $2: 1$ heart block, $0.25 \mathrm{sec}$. 
It is interesting that the $\mathbf{P}-\mathbf{R}$ interval with latent heart block with no dropped beats, the $\mathbf{P}-\mathbf{R}$ interval of the first response after a dropped beat, and the P-R interval with $2: 1$ heart block should all be so close- 0.24 to $0.27 \mathrm{sec}$. in these cases.

The correspondence of these three, both in average and in individual figures, and our observations that whatever the grade of heart block - whether there are dropped beats after two responses or after six or seven-the first P-R interval after the dropped beat averages $0.23 \mathrm{sec}$. and the last before the next dropped beat $0.35 \mathrm{sec}$. must be taken into account in any explanation of heart block.

The real difficulty has always been to explain why in one case a $P-R$ interval of $0.35 \mathrm{sec}$. gets no longer and is regularly followed by a response, and yet in another case a P-R interval that is shorter or nearly normal lengthens till it reaches a stage where a beat is dropped.

If the higher grades of heart block were always associated with the very long P-R intervals such as $0.35-0.40 \mathrm{sec}$., and the lower grades with shorter $P-R$ intervals such as $0.25-0.30$ sec., one could look on the defect of conductivity as the whole or almost the whole explanation. But when it is possible to have a $\mathrm{P}-\mathrm{R}$ interval of, say, $\mathbf{0 . 2 4} \mathrm{sec}$., with regular responses and no dropped beats or a $\mathrm{P}-\mathrm{R}$ interval of the same duration with dropped beats or with $2: 1$ block, a second factor must also be involved.

It seems that depression of excitability, the main explanation in the cases described by Hay, is also concerned in all these other cases. The separation of the function of cardiac muscle into its four divisions, of which conductivity and excitability are two, has been criticized, but clinical study of heart block suggests that these two at any rate are both involved in the production of most cases of heart block. Probably the same factors that affect conductivity also affect excitability of the ventricle, and the grade of heart block depends on the interaction of these two.

\section{SUMmaRY AND CONCLUSIONS}

Partial heart block with dropped beats is nearly always transient, so that it is rare to find a patient in whom this rhythm can be expected as a usual or even as a common finding.

At one time or another it was observed in nearly one sixth of a series that included all types of heart block, but this gives an exaggerated idea of its frequency because it was generally transient and of short duration.

In two thirds of the cases ( 25 out of 38 ) there was a known cause, active infection or treatment with digitalis. In 14 the cause was an acute infection, in 5 it was treatment with digitalis, and in 6 both causes combined. As would be expected, acute rheumatism was the most common infection ( 9 of 20 cases) ; but tonsillitis, without any suggestion that it was rheumatic, was often found.

The patients with dropped beats due to infections were mostly between 18 and 34 years of age. The outlook in this group was surprisingly good and the patient often recovered even to the stage of a normal P-R interval. As an exception the simultaneous association of tonsillitis and hyperthyroidism with dropped beats seemed of grave significance.

In the remaining third (13 cases) there was chronic heart disease and no very obvious reason why the dropped beats should have been found at the time they were, for here, too, they were generally transient. These were older patients, nearly all well over 60 years of age: all had chronic heart disease; high blood pressure and coronary atheroma were each the ætiological factor in one third, and in the remaining third there was myocardial disease without evidence of either of these factors.

In addition, some degree of heart block generally remained in the group of older patients, half of them having $2: 1$ heart block as a common or as their most usual rhythm. This was not so with the younger patients. Complete heart block also was uncommon in the group of younger patients with infections, but was present at some time in about one quarter of the older group. The regular sequence of dropped beats, $2: 1$ heart block, and finally complete heart block was observed, but was rare.

The length of the $\mathbf{P}-\mathbf{R}$ intervals was also studied. Progressive lengthening, but with a decreasing increment, was the rule, the increase of the second $P-R$ interval over the first being much larger than the subsequent increases. There were, however, exceptions. In about one eighth of the cases with dropped beats, these came without any gradual lengthening of the P-R interval (Hay's depression of excitability); these patients were mostly older ones with chronic heart disease.

For each grade of heart block up to a dropped beat after six responses, there were enough records to give some average figures, which have been shown in Table V and Fig. 6 and can be given more shortly as

$3: 2$ heart block; $0 \cdot 23,0 \cdot 35$ sec., dropped beat.

$4: 3$, , $, 0 \cdot 23,0 \cdot 30,0 \cdot 35$, d.b.

$5: 4 \quad " \quad$ " $\quad 0 \cdot 23,0 \cdot 285,0 \cdot 32,0 \cdot 35$, d.b 
It must, however, be repeated that these are only the average of figures that varied widely in the different cases. It is strange that the average and the range of the P-R intervals between the first response after and the last response before the dropped beat should be so constant, whether there is one dropped beat to $3,4,5$, or 6 responses. This finding and some of the other points that have been discussed suggest that the defect of conductivity is generally the condition which makes heart block likely, but that something else, probably excitability, decides if there will be block and, if so, of what grade it will be.

I should like to express my thanks to my colleagues at Guy's Hospital and at the National Hospital for Diseases of the Heart for allowing me to continue observations on some patients who were under their care. Without the help of Dr. S. Suzman as Clinical Assistant and Mr. F. H. Muir as technician, it would not have been possible to keep in touch with so many patients or to get so much information about patients who were generally first seen during busy routine sessions. Such work has obvious limitations and in some directions more could have been found out in a few days by intensive experimental observations on one patient. Nevertheless, the less complete study of a series of unselected cases gives other information that can only be obtained in this way and the two methods are complimentary. The loss of my longer paper-camera records of many of these patients as a result of enemy action has limited the study to shorter plate records.

Campbell, M. (1931). Lancet, 2, 180.

\section{REFERENCES}

- (1942). Brit. Heart J., 4, 131.

Hay, J. (1906). Lancet, 1, 139.

Lewis, T. (1925). The Mechanism and Graphic Registration of the Heart Beat, London, p. 177.

Wenkebach, K. F. (1904). Arhythmia of the Heart. Translated by T. Snowball ; Wm. Green \& Sons, Edinburgh and London. 